\title{
A Prescription Trend Analysis of Methylphenidate: Relation to Study Reports on Efficacy
}

\author{
Maruschka N. Sluiter ${ }^{1,2}$. Ymkje Anna de Vries ${ }^{1}$ - Lotte G. Koning ${ }^{1}$ - Eelko Hak ${ }^{3}$. Jens H. J. Bos ${ }^{3}$. \\ Catharina C. M. Schuiling-Veninga ${ }^{3} \cdot$ Laura Batstra $^{4} \cdot$ Jeannette M. Doornenbal ${ }^{2} \cdot$ Peter de Jonge $^{1}$
}

Published online: 16 October 2019

(c) The Author(s) 2019

\begin{abstract}
Use of methylphenidate in children has increased substantially, despite conflicting evidence regarding efficacy. In this study, prescription data were analyzed in relation to the publication of new evidence regarding efficacy. Incidence rates and prescribed doses of methylphenidate increased, with a decline during the last few years. Duration of use is still increasing. In half of the cases, starting dosages are higher than recommended in guidelines. There was little evidence that publication of new evidence directly influenced the use of methylphenidate. Recent and critical study findings should receive more attention to contribute to the development and use of treatment guidelines for ADHD and evidence-based methylphenidate use.
\end{abstract}

Keywords Attention deficit/hyperactivity disorder · Children and adolescents · Methylphenidate · Prescription trends · MTA

\section{Introduction}

In the Netherlands, as in many other Western countries (Bachmann et al. 2017; Stephenson et al. 2013; McCarthy et al. 2012; Zuvekas and Vitiello 2012), the number of methylphenidate (MPH) prescriptions for children has increased substantially over the past 20 years, even quadrupling from 2003 to 2013 (Health Council of the Netherlands 2014). In 2013, nearly $4.5 \%$ of Dutch children received MPH. This considerable increase may give the impression that MPH has

Electronic supplementary material The online version of this article (https://doi.org/10.1007/s10488-019-00983-6) contains supplementary material, which is available to authorized users.

Maruschka N. Sluiter

m.n.sluiter@rug.nl

1 Department of Developmental Psychology, University of Groningen, Grote Kruisstraat 2/1, 9721 TS Groningen, The Netherlands

2 Youth, Education and Society, Hanze University of Applied Sciences, Groningen, Groningen, The Netherlands

3 PharmacoTherapy, - Epidemiology \& -Economics, Groningen Research Institute of Pharmacy, University of Groningen, Groningen, The Netherlands

4 Department of Special Needs Education and Child Care, University of Groningen, Groningen, The Netherlands been shown to be unequivocally effective for the treatment of attention-deficit hyperactivity disorder (ADHD). However, research about the efficacy of ADHD medication for children has led to mixed results.

In 1999, the Multimodal Treatment Study of Children with ADHD (MTA) was published. The MTA study was the first study to examine the short- and long-term safety and relative efficacy of medication and behaviour therapy alone or in combination and compared these treatments to routine community care. The MTA study concluded that medication trounced behavioural therapy for children with ADHD; combining both treatments did not lead to better results compared to medication alone (Jensen 1999). However, after 10 months the difference in efficacy had become smaller (MTA Cooperative Group 2004; Schwarz 2013), and after 22 months the early benefits of medication had even vanished (Jensen et al. 2007). Post hoc analyses with naturalistic groups suggested that children who were still on medication were doing worse than those who had stopped using it (Jensen et al. 2007). Recent studies, including the third MTA follow-up (Molina et al. 2009), concluded that medication was efficacious in reducing ADHD behaviour in the short term (Schachter et al. 2011), but there was no evidence that this medication benefits children in the long term (Riddle et al. 2013; Smith et al. 2010; Vogt and Lunde 2018). The most recent MTA follow-up, a 16-year follow-up into 
adulthood, also found no evidence for long-term effects on symptom levels (Swanson et al. 2017). However, extended use of MPH can cause lasting growth suppression and may increase the risk of antisocial and criminal behaviour (Swanson et al. 2017).

In light of these findings, a decrease in the use of MPH worldwide might have been expected, yet previous research suggests this did not happen (Bachmann et al. 2017; Stephenson et al. 2013; McCarthy et al. 2012; Zuvekas and Vitiello 2012). This contradiction may be related to the fact that while the first MTA study results received a substantial amount of attention and publicity in scientific articles (Nieweg 2010; Schwarz 2013), the follow up studies did not. The first MTA study has now been cited 1580 times and still receives at least twice as many citations each year as the follow-up studies published in 2004 (243 citations), 2007 (237 citations), and 2009 (406 citations) (Web of Science 2017).

The initial MTA results served as the evidence base for many guidelines, including those in the Netherlands (Nieweg 2010). The Dutch guidelines (Multidisciplinaire richtlijn ADHD bij kinderen en jeugdigen 2005) describe ADHD as a neurodevelopmental disorder that should be treated with long-term medication therapy. This guideline was published in 2005, and the results of the MTA follow-up studies or other studies investigating the efficacy of ADHD medication have not led to revision of this guideline yet. Research does indicate that the translation of research findings into clinical practice takes a significant amount of time (Balas and Boren 2000), with estimated average of 17 years until widespread adoption in day-to-day clinical practice (Westfall et al. 2007). On the other hand, patent protection for new medication generally expires within 10 to 15 years of product launch (Aitken and Kleinrock 2017), so very rapid adoption of new medications is necessary in order for pharmaceutical companies to recoup their initial investments; hence, the time window of adoption may depend on the nature of the scientific findings, and more rapid changes in clinical practice are certainly possible.

To investigate the developments in MPH use in more detail, the current study contains a detailed trend analysis of MPH prescriptions in the Netherlands between 1995 and 2015. We investigated the incidence of MPH use in relation to the publication dates of the MTA study and its followup studies, as the initial study served as the evidence base for many guidelines and the follow ups revealed contradicting evidence, expecting an increase in incidence during the early years of the study period, followed by a decline from 2004. We also expected a decline in long-term use, as studies showing no evidence for long-term efficacy were published. New findings on the efficacy and side effects of MPH use may also have led to a decline in dosing of MPH, although these new findings were not included in guidelines. Hence, we also studied dosing of MPH between 1995 and 2015 and compared starting dosages with the Multidisciplinary Guideline ADHD to see if the dosing is in accordance with this guideline.

\section{Methods}

\section{Data Source}

The prescription data for this study were obtained from the pharmacy prescription database, IADB.nl. This database comprised more than 60 community pharmacies in the Netherlands and covers a population of approximately 600,000 people. It contains information about dispensed medications (ATC code, number of prescriptions, dosage of the dispensed drug, number of tablets to take daily, total amount of defined daily doses (DDD) dispensed) (Visser et al. 2013) as well as limited information about patients (age and gender). Patients are included upon receiving their first prescription in one of the participating pharmacies. This database provides virtually complete medication records, except for over the counter (OTC) drugs and medication dispensed during hospitalization. The population covered by IADB largely corresponds to the composition of the Dutch population, with a slight over-representation of the age-group of 18-33 years of age (Visser et al. 2013).

\section{Patient Selection}

We selected a cohort of young people aged between 4 and 18 at the time of their index MPH prescription. Participants were required to have been in the database for at least 1 year prior to their index MPH prescription without receiving MPH. This ensured that the index prescription was the first prescription of a treatment episode and hence we subsequently refer to the index prescription as the first prescription. However, it should be noted that participants may have had prior treatment episodes before entering the database. All patients were from municipalities in the northern or middle Netherlands. Because of the requirement that patients must have been in the database for at least 1 year prior to the first prescription, this study includes prescriptions filled between 1995 and 2015.

\section{Data Analysis}

To examine the influence of the publication of the MTA study and its subsequent follow-ups on MPH use, we split the time window of 1995-2015 up into shorter periods based upon the publication dates of these studies. Because the first, second, and third follow-ups were published shortly after one another, we only used the publication dates of the first 
and third follow-ups to split the full time window in order to ensure that each time period included a comparable amount of time points. This resulted in the following time periods:

- January 1995-December 1999 (from database initiation until the initial MTA publication);

- January 2000-April 2004 (from the initial MTA publication until publication of the first MTA follow-up);

- May 2004-May 2009 (from publication of the first MTA follow up until publication of the third MTA follow-up);

- June 2009-December 2015 (from publication of the third MTA follow-up until the end of data collection).

For the first research question considering the incidence of MPH prescriptions, we calculated the monthly incidence rate of MPH use by dividing the number of first prescriptions per month by the number of inhabitants in the database reference population aged between 4 and 18 (inclusive) in that year. Through a time series analysis (autoregressive integrating moving average, ARIMA), each period was compared with the subsequent period. Hence, we performed three time series analyses (period 1 vs. period 2, period 2 vs. period 3 , and period 3 vs. period 4 ). We investigated both level effects (sudden increases or decreases in the incidence rate) and slope (trend) effects (changes in the rate of increase or decrease in incidence compared to the preceding period). To take into account the correlated nature of time series data, we examined autocorrelation function (ACF) plots and incorporated lagged autocorrelations as required. Models with different lagged autocorrelations were compared with the Bayesian Information Criterion (BIC). Because incidence of MPH use showed a very strong seasonal pattern, with greatly reduced incidence in July (due to the summer vacation), we also examined improvement in model fit by including a dummy variable for the month July into the model.

For the second question about the proportion long-term users, we first calculated the duration of MPH use. A continuous period of MPH use was defined as a period during which no more than 1 year elapsed between consecutive MPH prescriptions, in accordance with Dutch pharmacists' guidelines. For participants with multiple episodes of use, we only included the first episode. The duration of use was defined as the difference between the fill date of the last prescription and the first prescription within an episode. We then calculated the proportion of long-term users of all MPH users (duration $>2$ years) for every month and performed a time series analysis to compare the time periods, as for the first question. In our main analysis, we considered every person exiting the database within the first 2 years after the first MPH prescription to be a short-term user; sensitivity analyses examined the effect of defining these persons as long-term users or of excluding these persons. Additionally, Kaplan-Meier curves were used to estimate the median duration of use for each time period. Right censoring was used to censor the data of patients who exited the database less than 1 year after their last MPH prescription or whose last MPH prescription was dispensed less than 1 year before the end of data collection (December 2015).

For the third question, the dosage of MPH over the years was analyzed. The starting dose was defined as the dosage of the first prescription. For participants who received multiple prescriptions on the same day, the prescription with the lowest dose was selected. However, for participants who received prescriptions for both an immediate-release (IR) and a controlled-release (CR) formulation of MPH, we added the dosages together, under the assumptions that these prescriptions would be taken concurrently. We excluded participants with implausible starting dosages $(0 \mathrm{mg} / \mathrm{day}$ or $>60 \mathrm{mg} / \mathrm{day})$. A period of maintenance was defined as a period of at least two prescriptions (after the first prescription) in which the dosage remained stable. If a participant had multiple such periods, we selected the period with the highest dose. For participants who received both MPH IR and CR during the same time period, we added the doses together. We excluded participants with implausible dosages $(0 \mathrm{mg} /$ day or $>120 \mathrm{mg} /$ day $)$. Subsequently, by using a Kruskal-Wallis test we tested if there were any significant differences in starting or maintenance dosage between the time periods. If the Kruskal-Wallis test was significant, we further analyzed the differences with Dunns post hoc test.

For the fourth question, we compared the starting dose of the first prescription to the dosage recommended by the Multidisciplinary Guideline for ADHD (Multidisciplinaire richtlijn ADHD bij kinderen en jeugdigen 2005). This guideline recommends initiating MPH treatment with $5(2 \times 2.5) \mathrm{mg} /$ day for children aged below 6 and with $10(2 \times 5)$ or $15(3 \times 5)$ $\mathrm{mg} /$ day for children aged 6 or older. When initiating treatment with MPH CR, the recommended starting dose is $18 \mathrm{mg} /$ day. A prescription was considered to be not in accordance with the guidelines if the dosage was higher than these recommendations. Because the guidelines for the maintenance dose are based upon body weight and this information was not included in the database, we did not compare the maintenance dose to the guideline. The adherence proportion was compared for all time periods using time series analysis. For all times series analyses an $\alpha$ of 0.005 was used (instead of 0.05 ) to reduce the chance of false positives due to multiple testing.

\section{Results}

\section{Demographics}

Between 1995 and 2015, a total of 10,877 patients (7981 (73\%) boys) received a first prescription for MPH. The 
mean age was $10.2(\mathrm{SD}=3.7)$ and the median age was 9 $(\mathrm{IQR}=7-13)$. Although most patients were male, the percentage girls increased with age to an almost equal distribution at eighteen. The distribution of age and gender is provided in supplemental Table 1.

\section{Incidence}

Figure 1 shows the incidence rate of first MPH prescriptions per month over the period 1995-2015. The figure shows strong seasonal fluctuations and an overall increasing trend, with periods of decrease in 2000-2002 and from 2011 onward.

Based upon the ACF plots and the Bayesian Information Criterion (BIC) of the different models, we included a lag-1 and a lag-12 (yearly) autocorrelation and a dummy variable for the month July in the ARIMA models. The results of the time series analysis (Table 1) showed a statistically significant, positive slope for the incidence during period 1 . Between time period 1 and 2, the slope decreased significantly (but remained positive) $(\mathrm{p}<0.001)$ and there was no level effect $(p=0.054)$. Between period 2 and 3 there was an increasing trend effect $(\mathrm{p}=0.006)$, and there was no significant level effect $(\mathrm{p}=0.90)$, while between period 3 and 4 there was a significant decrease in the slope $(p<0.001)$, resulting in a decreasing trend and again no significant level effect $(\mathrm{p}=0.51)$.

As the negative level effect and the decrease in slope between period 1 and 2 is opposite what may be expected based on previous findings in other countries and the publication of the initial MTA study, this phenomenon was further analyzed. This analysis implies a search for another factor that may have influenced prescription behaviour. Pieters e.a. (in Bolt and De Goei 2008) stated that the tone of
Table 1 ARIMA model parameters comparing incidence in time periods

\begin{tabular}{lcr}
\hline & Estimate & \multicolumn{1}{c}{ Sig. } \\
\hline Comparison 1-2 & & \\
Slope in initial time period & .06 & $<.001$ \\
Difference in slope between time periods & -.04 & $<.001$ \\
Level effect & -.72 & .054 \\
Comparison 2-3 & & \\
Slope in initial time period & .02 & .099 \\
Difference in slope between time periods & .04 & .006 \\
Level effect & .05 & .897 \\
Comparison 3-4 & & \\
Slope in initial time period & .06 & $<.001$ \\
Difference in slope between time periods & -.08 & $<.001$ \\
Level effect & .29 & .510 \\
\hline
\end{tabular}

Dutch media reports about ADHD was changing and becoming more critical around 1999. In 2000, a critical television documentary about the alarming increase in use of MPH in children even led to questions in the Dutch parliament (Zembla 2000; Bolt and De Goei 2008). A similarly critical documentary was aired in the Netherlands in 2010 (Zembla 2010).

\section{Long-Term Use}

Figure 2 shows the proportion of long-term MPH users over time.

Time series analysis indicates that the proportion of longterm users is relatively stable at approximately $50 \%$ of users (Table 2). There is a decreasing trend effect between period 3 and $4(\mathrm{p}=.018)$, suggesting a decreasing proportion of
Fig. 1 Incidence of MPH prescriptions for every month between January 1995 and December 2015. *Release of critical documentary in the Netherlands

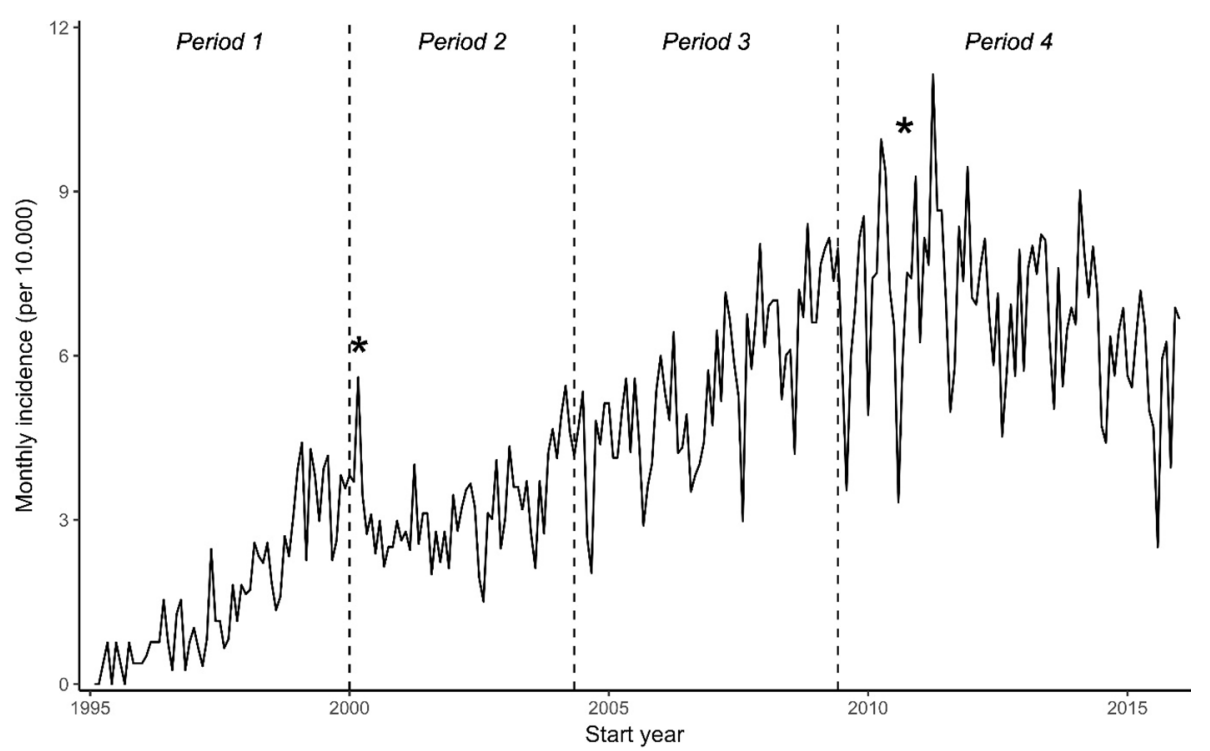


Fig. 2 Proportion of long-term users of all MPH users for every month between January 1995 and December 2012

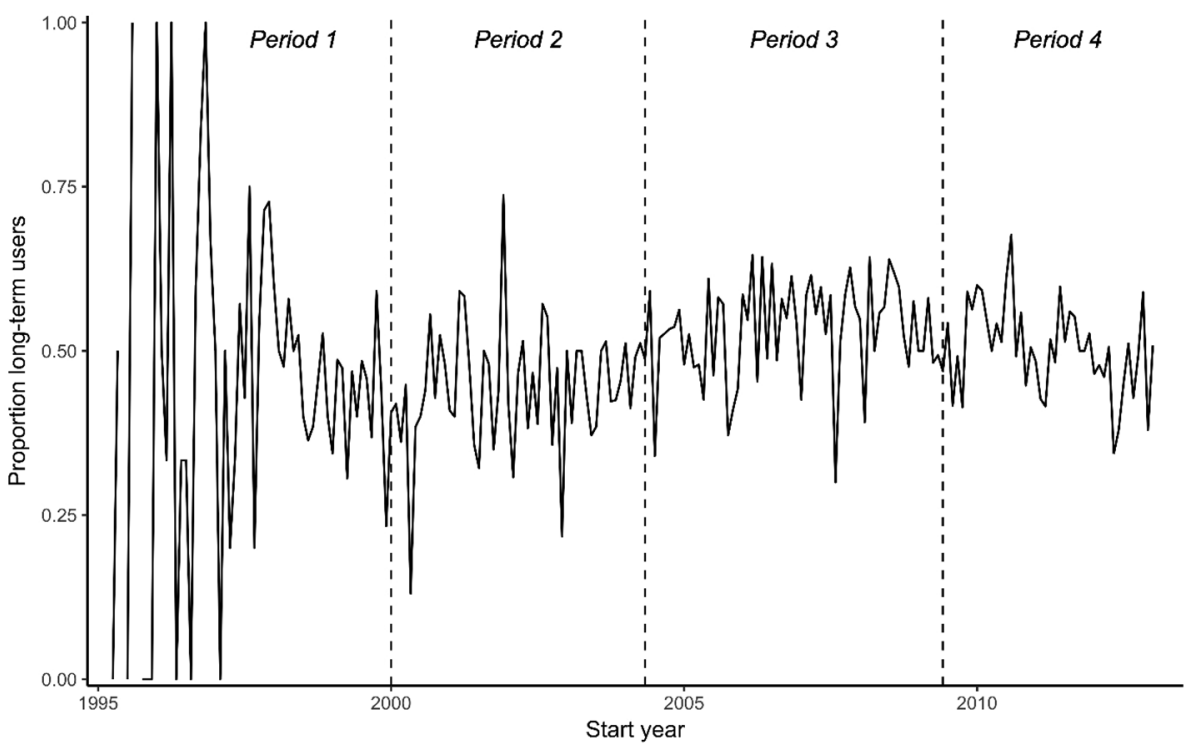

Table 2 ARIMA model parameters comparing proportion long-term users in time periods

\begin{tabular}{lrr}
\hline & Estimate & Sig. \\
\hline Comparison 1-2 & .002 & .370 \\
$\quad$ Initial slope & -.001 & .806 \\
Difference in slope between time periods & -.064 & .408 \\
Level effect & & \\
Comparison 2-3 & .001 & .259 \\
Initial slope & .000 & .908 \\
Difference in slope between time periods & .040 & .218 \\
Level effect & & \\
Comparison 3-4 & .001 & .141 \\
Initial slope & -.002 & .018 \\
Difference in slope between time periods & -.016 & .563 \\
Level effect & & \\
\end{tabular}

long-term users in period 4 . However, sensitivity analyses did not confirm this decrease in slope.

Kaplan-Meier curves indicated that the median duration of use increased significantly (Table 3 ). For period 4 , a median duration could not be estimated because fewer than $50 \%$ of users discontinued treatment before right censoring, but the first quartile of duration of use suggests that the duration is still increasing.

\section{Starting and Maintenance Dosage}

Figure 3 shows the percentage of starting (Fig. 3a) and maintenance (Fig. 3b) doses within a given dose range for each time period.

Starting dosage is increasing between period 1 and 2, with a larger percentage of prescriptions at high doses in
Table 3 Q1 and median duration in years of prescriptions per time period

\begin{tabular}{lll}
\hline Time period & Q1 & Median \\
\hline 1 & .18 & 1.87 \\
2 & .21 & 2.07 \\
3 & .54 & 3.25 \\
4 & 1.02 & NA \\
\hline
\end{tabular}

period 2. In period 4 more low doses are prescribed. The percentage of prescriptions at high doses is unchanged, so these lower doses are prescribed instead of medium doses. For the maintenance dose, there is an increase in dosage between period 1 and 3, with a larger percentage of MPH users receiving higher doses in periods 2 and 3. In period 4, more MPH users are prescribed a lower dose and fewer high doses are prescribed. The mean dose parallels these trends, although there are few shifts in the median dose over time (Table 4).

The Kruskal-Wallis test shows a statistically significant difference between starting doses in different time periods $(\mathrm{H}=14.383, \mathrm{p}=.002)$, as well as for maintenance doses $(\mathrm{H}=299.74, \mathrm{p}<.001)$. Dunns post hoc test (Table 5) shows that for starting dose only the distributions of period 2 and 4 and period 3 and 4 differ significantly from each other, with significantly lower doses in period 4 , and for maintenance dose the distribution in all time periods differs significantly from each other; until period 3 the dosage is significantly increasing, but the distribution of dosage in period 4 is significant lower than in the other periods.

\section{Guideline Compliance}

Figure 4 shows the proportion of first prescriptions that were in accordance with the Multidisciplinary Guideline 

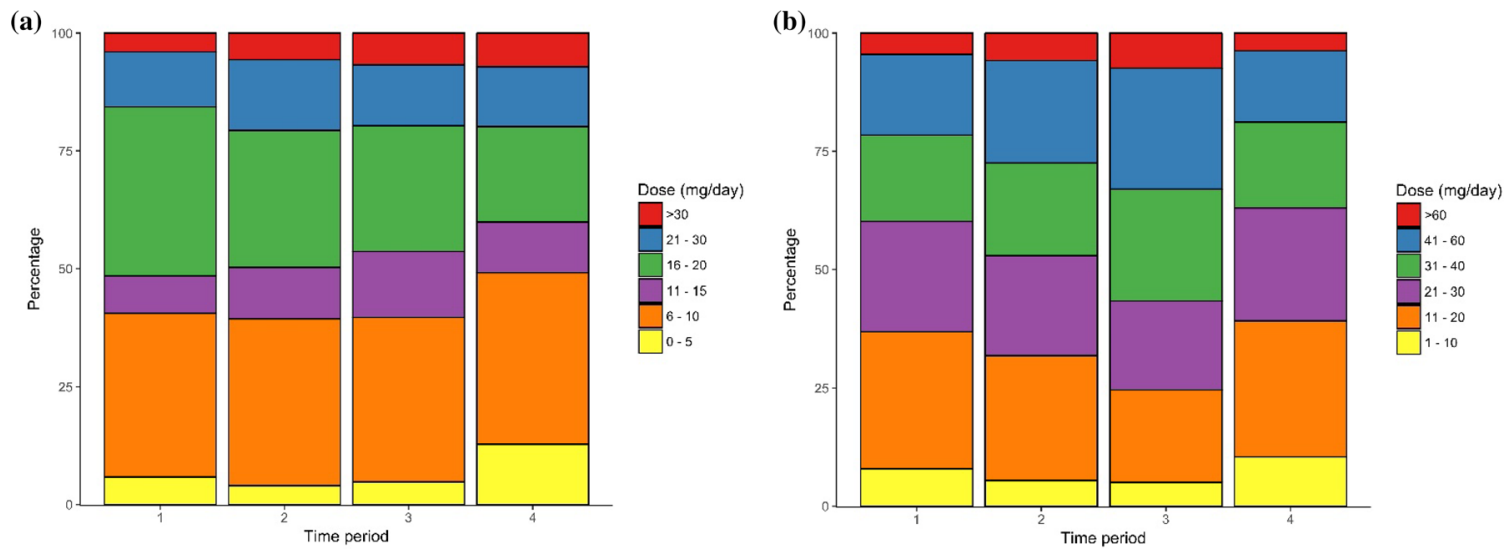

Fig. 3 Percentage of patients with a specific $\mathbf{a}$ starting dose and $\mathbf{b}$ maintenance dose per time period

Table 4 Median and mean start and maintenance dose in mg/day per time period

\begin{tabular}{llll}
\hline & Time period & Median dose & Mean dose \\
\hline Start dose & 1 & 19 & 17.08 \\
& 2 & 15 & 17.95 \\
& 3 & 15 & 17.57 \\
Maintenance dose & 1 & 15 & 16.55 \\
& 2 & 30 & 32.96 \\
& 3 & 30 & 35.31 \\
& 4 & 36 & 37.97 \\
\hline
\end{tabular}

Table 5 Dunns post hoc test comparison dosage in time periods

\begin{tabular}{llrr}
\hline & Comparison & \multicolumn{1}{c}{ Z } & P. adj \\
\hline Start dose & $1-2$ & -1.27 & .828 \\
& $1-3$ & -.61 & .541 \\
$2-3$ & 1.04 & .892 \\
& $1-4$ & .93 & .703 \\
& $2-4$ & 3.28 & .006 \\
Maintenance dose & $3-4$ & 2.83 & .023 \\
& $1-2$ & -2.84 & .009 \\
& $1-3$ & -6.40 & $<.001$ \\
& $2-3$ & -4.44 & $<.001$ \\
& $1-4$ & 2.46 & .014 \\
& $2-4$ & 7.92 & $<.001$ \\
& $3-4$ & 16.98 & $<.001$ \\
\hline
\end{tabular}

for ADHD (Multidisciplinaire richtlijn ADHD bij kinderen en jeugdigen 2005) in terms of dosing. Time series analyses were done to compare the time periods (Table 6). Based on the results of the ACF, lag-6, lag-7 and lag-10 autocorrelations were incorporated into the first model comparing period 1 and 2; no significant autocorrelation was present in the other periods.

The time series analysis showed that no significant change in guideline compliance took place between period 1 and 2 . Between period 2 and 3 there is a significant positive level effect $(\mathrm{p}=.001)$, but no significant trend effect $(\mathrm{p}=.468)$, indicating a relatively abrupt increase in guideline compliance. Finally, between period 3 and 4 there is an increasing trend effect $(\mathrm{p}=.009)$, and no significant level effect $(\mathrm{p}=.323)$.

\section{Discussion}

\section{Principal Findings}

We examined the incidence of MPH use and its relationship to the publication of important evidence for or against the use of MPH. The incidence shows an overall increasing trend, with two periods of decline that appeared unrelated to the MTA publications. The proportion of long-term users was relatively stable over time at approximately $50 \%$, while the duration of use was increasing, despite the publication of evidence that does not support long-term efficacy (Riddle et al. 2013; Smith et al. 2010; Vogt and Lunde 2018). The dosing of MPH decreased in the last few years after a period of increase. The decline in starting dose started prior to the decline in maintenance dose. The proportion of guideline concordant use slowly increased over the years.

The generally increasing trend of MPH use, which is in line with previous research (Bachmann et al. 2017; Stephenson et al. 2013; McCarthy et al. 2012; Zuvekas and Vitiello 2012), suggests that several negative study reports on efficacy of MPH did not immediately lead to significant changes in MPH use. However, a delayed effect is possible (Balas and Boren 2000). Furthermore, the decline in MPH prescriptions in 2000-2002 is not seen in other 
Fig. 4 Guideline compliance of starting dose for every month between January 1995 and December 2015

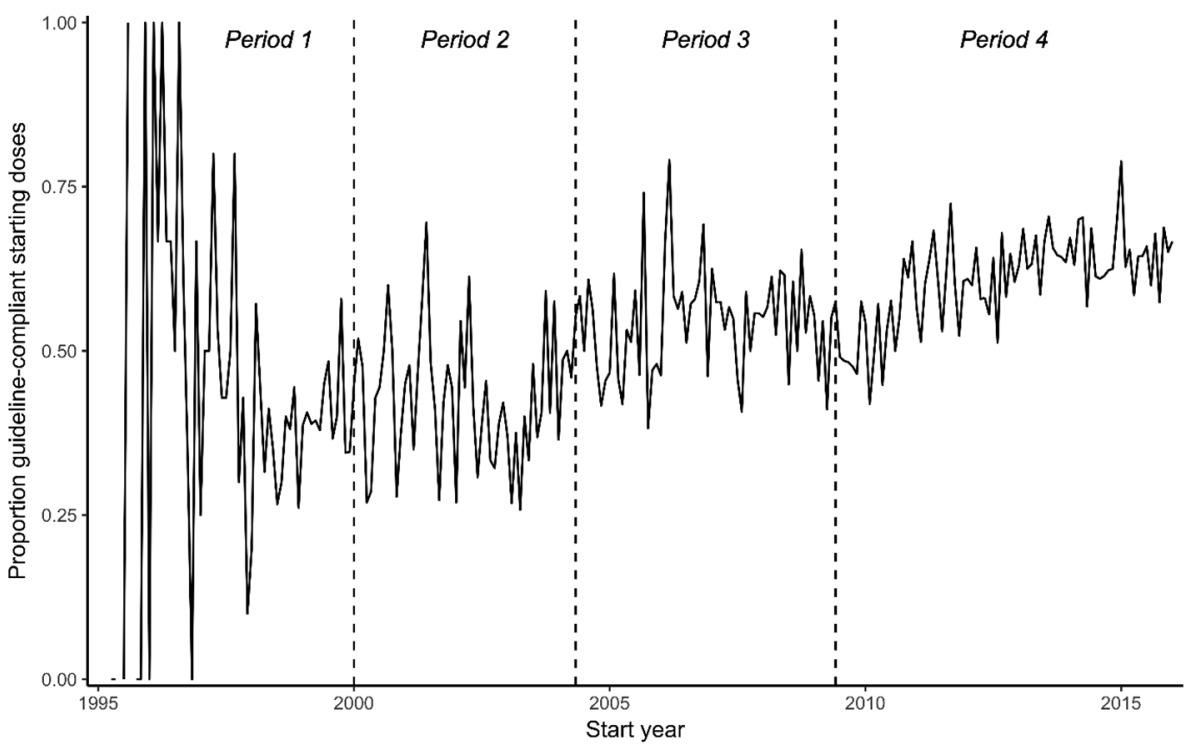

Table 6 ARIMA model parameters comparing guideline compliance in time periods

\begin{tabular}{lrr}
\hline & Estimate & Sig. \\
\hline Comparison 1-2 & -.003 & \\
$\quad$ Initial slope & .002 & .037 \\
Difference in slope between time periods & .086 & .183 \\
Level effect & & \\
Comparison 2-3 & .000 & .601 \\
Initial slope & .001 & .468 \\
Difference in slope between time periods & .119 & .001 \\
Level effect & & \\
Comparison 3-4 & .000 & .492 \\
Initial slope & .002 & .009 \\
Difference in slope between time periods & -.023 & .323 \\
Level effect & & \\
\end{tabular}

studies about MPH prescriptions in the world (e.g. Stephenson et al. 2013; Zuvekas and Vitiello 2012), which probably indicates the influence of a specific national factor. Media have been suggested to play a significant role in the substantial expansion of ADHD diagnoses and MPH use (Bolt and de Goei 2008), but the previously mentioned critical Dutch television documentary aired in 2000, just before the decline in incidence rates in 2000-2002, may be an example of the media having an opposite effect. The similarly critical Dutch documentary in 2010 and other critical media attention may also have influenced the second decline in incidence rates around 2011. The followup studies may seem to have few effects on prescription behaviour in part because the results of the follow-up studies have not yet led to revision of the 2005 guideline.
The overall increasing trend in guideline compliance, especially since around 2005 , is a positive development that might be expected since the Multidisciplinary Guideline for ADHD (Multidisciplinaire richtlijn ADHD bij kinderen en jeugdigen 2005) was published in 2005. However, around half of prescriptions are still not in accordance with the guideline regarding to dosing, and this guideline itself may be outdated, indicating that there remains much room for improvement.

\section{Strengths and Limitations}

This study has several strengths. First, we included a large group of participants and a large time window with recent data. Second, we did not only analyze the number of prescriptions, but gave a more detailed analysis of prescription data by also analyzing other aspects such as duration of use and dosing, in contrast to many other studies. Finally, the database used allowed us to use all available data on prescriptions, resulting in a representative sample without selection bias.

This study also has some limitations. Because the IADB database was still expanding between 1994 and 1999, there is limited and hence noisy data in this time period. This limited our ability to accurately detect trends in the period before the publication of the MTA study.

Another limitation is that the database did not include information on the indication. Since MPH is not only prescribed for ADHD, but also for narcolepsy and other indications, some of the prescriptions that we assumed to be for ADHD may not have been. However, in the Netherlands only 6000 to 8000 people suffer from narcolepsy (Nederlandse vereniging narcolepsie 2017) and the vast majority of MPH prescriptions to children are for ADHD and related problems (Donker et al. 2005). Furthermore, MPH is not the only 
medication for ADHD, so overall medication use among children with ADHD is likely to be somewhat higher than we found. However, MPH is prescribed to the vast majority of children with ADHD who receive medication $(86.8 \%$ in 2015 ) and the multidisciplinary guideline also recommends MPH as the initial treatment, with other medications recommended only as second-line options. In addition, it seems unlikely that this would have affected the trends over time. It is, however, possible that participants switched to other medication after discontinuing MPH, but we did not check this. We also did not correct for the use of other ADHD medications prior to a first MPH prescription, but the number of children using other ADHD medications prior to a first MPH prescription was negligible.

We also have no information about participants who exit the database. They may have left the database because of a move and have continued using MPH, or they may have discontinued MPH. To examine long-term use, we considered every person exiting the database within the first 2 years after the first MPH prescription as a short-term user. This approach may have led to an underestimation of the proportion of long-term users. If every person exiting the database within the first 2 years after the first MPH prescription was actually a long-term user, the percentage long-term users would have been around $60 \%$, indicating the upper boundary of the percentage of long-term users.

Furthermore, although we found no direct effect of the MTA publications on prescription behaviour, it is possible that there might be a delayed effect. It might take time for study results to reach society, especially for follow-up studies. The unexpected finding that MPH prescriptions decreased after publication of the MTA study led us to search for possible other influential factors. This showed a possible influence of popular media, instead of the influence of scientific articles. However, we may have missed other influencing factors on MPH prescriptions, for example legislation or costs (Magnée et al. 2014). Furthermore, pharmaceutical companies could have influenced prescription trends by advertising and promoting positive findings on medication use (Batstra 2017; Windmeijer et al. 2006), although the exact influence is hard to determine (Leeflang and Wieringa 2010). The influence of potential other factors on prescription trends that we did not include in our research, could be investigated in future research.

Although this study contains only Dutch data, the findings may have broader implications, since prescription trends are comparable worldwide (Bachmann et al. 2017; Stephenson et al. 2013; McCarthy et al., 2012; Zuvekas and Vitiello 2012) and the discrepancy between research evidence and clinical practice is also a more general phenomenon (Mclennan et al. 2006). In future research it would be interesting to analyse the same questions for other countries, to establish a more complete view and investigate whether the results of this study can be generalized. Since our results indicate there seems to be a slight change in prescription trends for children with ADHD in the past few years, future research could also investigate whether this trend continues and incidence rates and dosing continue declining.

\section{Conclusions}

The increase in medication use for children with ADHD in the past 20 years is alarming, although there appears to be a slight decrease in recent years. Although the long-term prescription trends may appear to be dominated by the initial positive findings of the MTA study, we did not see a direct effect of this initial publication. Additionally, we only see small effects of the follow-ups on prescription behaviour in the last time period. Dumas-Mallet et al. (2017) concluded that journalists preferentially cover initial findings, although these are often contradicted by meta-analyses, and rarely inform the public when they are disconfirmed. Prescription behaviour finally seems to change in the last few years, as reflected in decreased prescription rates, decreased dosing, and increased guideline compliance, although there remains much room for improvement. Long-term users particularly need attention, as this group is hardly decreasing and the prescription duration is even increasing. In summary, our results show no evidence that the publication of new scientific evidence significantly affects prescription trends. However, the translation of research evidence into practice and the adoption of evidence-based practices may take a long time (Balas and Boren 2000). Instead, it seems plausible that popular media may have exerted a greater influence. Therefore, researchers need to consider the way they could influence society with recent findings. Attention to contemporary knowledge can contribute to more evidence-based MPH use in children with ADHD.

Funding This study received no specific funding.

\section{Compliance with Ethical Standards}

Conflict of interest All authors declare that they have no conflict of interest.

Ethical Approval This article does not contain any studies with human participants or animals performed by any of the authors.

Open Access This article is distributed under the terms of the Creative Commons Attribution 4.0 International License (http://creativeco mmons.org/licenses/by/4.0/), which permits unrestricted use, distribution, and reproduction in any medium, provided you give appropriate credit to the original author(s) and the source, provide a link to the Creative Commons license, and indicate if changes were made. 


\section{References}

Aitken, M., \& Kleinrock, M. (2017). Lifetime trends in biopharmaceutical innovation: Recent evidence and implications. Report by the QuintilesIMS Institute. Retrieved June 27, 2019 from https:// www.statnews.com/wp-content/uploads/2017/01/Lifetime_Trend s_in_Biopharmaceutical_Innovation.pdf.

Bachmann, C. J., Wijlaars, L. P., Kalverdijk, L. J., Burcu, M., Glaeske, G., Schuiling-Veninga, C. C., et al. (2017). Trends in ADHD medication use in children and adolescents in five western countries, 2005-2012. European Neuropsychopharmacology, 27(5), 484-493.

Balas, E. A., \& Boren, S. A. (2000). Managing clinical knowledge for health care improvement. Yearbook of Medical Informatics, 9(01), 65-70.

Batstra, L. (2017). ADHD: Macht en misverstanden. Hilversum: Uitgeverij Lucht.

Bolt, T., \& de Goei, L. (2008). Kinderen van hun tijd: zestig jaar kinder-en jeugdpsychiatrie in Nederland, 1948-2008. Assen: Uitgeverij Van Gorcum.

Donker, G. A., Groenhof, F., \& van der Veen, W. J. (2005). Toenemend aantal voorschriften voor methylfenidaat in huisartspraktijken in Noordoost-Nederland, 1998-2003. Nederlands Tijdschrift voor Geneeskunde, 149, 1742-1747.

Dumas-Mallet, E., Smith, A., Boraud, T., \& Gonon, F. (2017). Poor replication validity of biomedical association studies reported by newspapers. PLoS ONE, 12(2), e0172650.

Health Council of the Netherlands. (2014). ADHD: Medication and society. The Hague: Health Council of the Netherlands; publication no. 2014/19.

Jensen, P. S. (1999). A 14-month randomized clinical trial of treatment strategies for attention-deficit/hyperactivity disorder. Archives of General Psychiatry, 56(12), 1073-1086.

Jensen, P. S., Arnold, L. E., Swanson, J. M., Vitiello, B., Abikoff, H. B., Greenhill, L. L., et al. (2007). 3-year follow-up of the NIMH MTA study. Journal of the American Academy of Child and Adolescent Psychiatry, 46(8), 989-1002.

Landelijke Stuurgroep Multidisciplinaire Richtlijnontwikkeling. (2005). Multidisciplinaire Richtlijn ADHD; Richtlijn Voor de Diagnostiek en Behandeling van ADHD bij Kinderen en Jeugdigen. Trimbos-instituut Utrecht.

Leeflang, P. S., \& Wieringa, J. E. (2010). Modeling the effects of pharmaceutical marketing. Marketing Letters, 21(2), 121-133.

Magnée, T., Verhaak, P., Boxem, R., \& Onderhoud, D. B. C. (2014). Verschuivingen van de tweedelijns geestelijke gezondheidszorg naar de eerstelijn en gevolgen daarvan voor de benodigde beroepsbeoefenaren: 2009-2012.

McCarthy, S., Wilton, L., Murray, M. L., Hodgkins, P., Asherson, P., \& Wong, I. C. (2012). The epidemiology of pharmacologically treated attention deficit hyperactivity disorder (ADHD) in children, adolescents and adults in UK primary care. BMC Pediatrics, 12(1), 78

McLENNAN, J. D., Wathen, C. N., MacMILLAN, H. L., \& Lavis, J. N. (2006). Research-practice gaps in child mental health. Journal of the American Academy of Child and Adolescent Psychiatry, 45(6), 658-665.

Molina, B. S., Hinshaw, S. P., Swanson, J. M., Arnold, L. E., Vitiello, B., Jensen, P. S., et al. (2009). The MTA at 8 years: Prospective follow-up of children treated for combined-type ADHD in a multisite study. Journal of the American Academy of Child and Adolescent Psychiatry, 48(5), 484-500.

MTA Cooperative Group. (2004). National Institute of Mental Health Multimodal Treatment Study of ADHD follow-up: 24-month outcomes of treatment strategies for attention-deficit/hyperactivity disorder. Pediatrics, 113(4), 754-761.
Nederlandse vereniging narcolepsie (n.d.). Welkom. Retrieved August 15, 2017 from www.narcolepsie.nl.

Nieweg, E. H. (2010). Is ADHD-medicatie na 2-3 jaar uitgewerkt? Over de verrassende, maar weinig bekende follow-up van het MTA-onderzoek. Tijdschrift voor psychiatrie, 52(4), 245-254.

Riddle, M. A., Yershova, K., Lazzaretto, D., Paykina, N., Yenokyan, G., Greenhill, L., et al. (2013). The preschool attention-deficit/ hyperactivity disorder treatment study (PATS) 6-year follow-up. Journal of the American Academy of Child and Adolescent Psychiatry, 52(3), 264-278.

Schachter, D., Tharmalingam, S., \& Kleinman, I. (2011). Informed consent and stimulant medication: Adolescents' and parents' ability to understand information about benefits and risks of stimulant medication for the treatment of attention-deficit/hyperactivity disorder. Journal of Child and Adolescent Psychopharmacology, 21(2), 139-148

Schwarz, A. A. D. H. D. (2013). ADHD experts re-evaluate study's zeal for drugs. New York Times, A11.

Smith, G., Jongeling, B., Hartmann, P., Russel, C., \& Landau, L. (2010). Raine ADHD study: Long-term outcomes associated with stimulant medication in the treatment of $A D H D$ in children. Perth: Government of Western Australia Department of Health.

Stephenson, C. P., Karanges, E., \& McGregor, I. S. (2013). Trends in the utilisation of psychotropic medications in Australia from 2000 to 2011. Australian and New Zealand Journal of Psychiatry, 47(1), 74-87.

Swanson, J. M., Arnold, L. E., Molina, B. S., Sibley, M. H., Hechtman, L. T., Hinshaw, S. P., et al. (2017). Young adult outcomes in the follow-up of the multimodal treatment study of attention-deficit/ hyperactivity disorder: Symptom persistence, source discrepancy, and height suppression. Journal of Child Psychology and Psychiatry, 58(6), 663-678.

Visser, S. T., Schuiling-Veninga, C. C. M., Bos, J. H. J., de Jong-van den Berg, L. T. W., \& Postma, M. J. (2013). The population-based prescription database IADB.nl: Its development, usefulness in outcomes research and challenges. Expert Review of Pharmacoeconomics and Outcomes Research, 13(3), 285-292. https://doi. org/10.1586/erp.13.20.

Vogt, H., \& Lunde, C. (2018). Drug treatment of ADHD-tenuous scientific basis. Tidsskrift for den Norske laegeforening: tidsskrift for praktisk medicin, ny raekke. https://doi.org/10.4045/tidss kr.17.0917.

Web of Science. (2017). Retrieved May 31, 2017 from https://apps. webofknowledge.com/WOS_GeneralSearch_input.do?produ $\mathrm{ct}=$ WOS\&search_mode $=$ GeneralSearch $\&$ SID $=$ P1cET5N2IB ATd1JXZY4\&preferencesSaved $=$.

Westfall, J. M., Mold, J., \& Fagnan, L. (2007). Practice-based research-"Blue Highways" on the NIH roadmap. JAMA, 297(4), 403-406.

Windmeijer, F., De Laat, E., Douven, R., \& Mot, E. (2006). Pharmaceutical promotion and GP prescription behaviour. Health Economics, 15(1), 5-18.

Zembla. (2000). Kinderen aan de pil. Broadcasted March 7, 2000, The Netherlands.

Zembla. (2010). De ADHD-hype. Broadcasted September 18, 2010, The Netherlands.

Zuvekas, S. H., \& Vitiello, B. (2012). Stimulant medication use in children: A 12-year perspective. American Journal of Psychiatry, 169(2), 160-166.

Publisher's Note Springer Nature remains neutral with regard to jurisdictional claims in published maps and institutional affiliations. 